\title{
Gut integrity in critical illness
}

\author{
Shunsuke Otani ${ }^{1,2,3}$ and Craig M. Coopersmith ${ }^{1 *}$ (D)
}

\begin{abstract}
Background: The gut is hypothesized to be the "motor" of critical illness. Under basal conditions, the gut plays a crucial role in the maintenance of health. However, in critical illness, all elements of the gut are injured, potentially worsening multiple organ dysfunction syndrome.

Main body: Under basal conditions, the intestinal epithelium absorbs nutrients and plays a critical role as the firstline protection against pathogenic microbes and as the central coordinator of mucosal immunity. In contrast, each element of the gut is impacted in critical illness. In the epithelium, apoptosis increases, proliferation decreases, and migration slows. In addition, gut barrier function is worsened via alterations to the tight junction, resulting in intestinal hyperpermeability. This is associated with damage to the mucus that separates the contents of the intestinal lumen from the epithelium. Finally, the microbiome of the intestine is converted into a pathobiome, with an increase in disease-promoting bacteria and induction of virulence factors in commensal bacteria. Toxic factors can then leave the intestine via both portal blood flow and mesenteric lymph to cause distant organ damage.

Conclusion: The gut plays a complex role in both health and critical illness. Here, we review gut integrity in both health and illness and highlight potential strategies for targeting the intestine for therapeutic gain in the intensive care unit.

Keywords: Gut, Intestine, Bacteria, Sepsis, Intensive care unit, Microbiome, Critical illness, Epithelium, Pathobiome, Apoptosis
\end{abstract}

\section{Background}

The gut has long been hypothesized to be the "motor" of critical illness [1-6]. The original biological explanation behind this theory is that critical illness induces intestinal hyperpermeability, leading to bacterial translocation via the portal circulation, leading to subsequent systemic infection and distant organ damage. In addition, studies over the past 20 years have demonstrated multiple additional methods in which the intestine can drive both local and distant injury.

In isolation, each component of the gut is severely compromised by critical illness, leading to both local and distant organ damage. Further, crosstalk between components of the gut and distant organs exacerbates cellular and organ injury. This review describes gut integrity in health and in critical illness, and potential ways

\footnotetext{
* Correspondence: cmcoop3@emory.edu

${ }^{1}$ Department of Surgery and Emory Critical Care Center, Emory University School of Medicine, 101 Woodruff Circle, Suite WMB 5105, Atlanta, GA 30322, USA

Full list of author information is available at the end of the article
}

in which the gut integrity can potentially be targeted as a therapeutic target in the ICU.

\section{The gut in health}

\section{The intestinal epithelium}

The gut is covered by a single-cell layer epithelium with a surface area of $30 \mathrm{~m}^{2}$, similar in size to half a badminton court [7]. The intestinal epithelium plays a role in managing host homeostasis and plays a critical role as the first-line protection against pathogenic microorganisms and as the central coordinator of mucosal immunity [8]. The intestinal epithelium also communicates with gut-associated lymph tissue and produces hormones, cytokines, and antimicrobial peptides. The single-cell layer intestinal epithelium is covered by a mucus layer which prevents direct contact between the epithelium and luminal contents [9].

The gut is a continuously renewing organ with the majority of cells turning over within 1 week. Intestinal stem cells reside near the base of crypts of Lieberkühn and can be identified by staining for the biomarker leucine-rich repeat-containing $\mathrm{G}$ protein-coupled receptor (Lgr) 5, which is present in stem cells but not the

(c) The Author(s). 2019 Open Access This article is distributed under the terms of the Creative Commons Attribution 4.0 International License (http://creativecommons.org/licenses/by/4.0/), which permits unrestricted use, distribution, and 
surrounding Paneth cells. Renewal and differentiation of $\mathrm{Lgr}^{+}$intestinal stem cells is modulated by clusters of differentiation (CD) $4^{+} \mathrm{T}$ helper cells [10], whereas their apoptosis and regeneration are mediated by the protein ARTS (a Septin-4 isoform) which induces cell death by translocating from the mitochondria to the cytosol where it binds to and antagonizes the X-linked inhibitor of apoptosis [11]. In addition, intestinal stem cells express the transmembrane protein toll-like receptor (TLR) 4, which regulates their proliferation and apoptosis through activation of p53-upregulated modulator of apoptosis (PUMA), which interacts with anti-apoptotic factors, thereby allowing pro-apoptotic signaling to the mitochondria [12].

Intestinal stem cells migrate up the crypt where they divide into daughter cells. Upon leaving the crypt, small intestinal epithelial cells enter the villus where they differentiate into (a) absorptive enterocytes (by far the most numerous cell type); (b) mucus-producing goblet cells, which also secrete anti-microbial proteins, chemokines, and cytokines [13]; (c) hormone-producing enteroendocrine cells; and (d) tuft cells which initiate mucosal immunity against parasitic infections [14]. As cells reach the tip of the villus, they either die by apoptosis or are exfoliated whole into the lumen. In contrast to other intestinal epithelial cell types, Paneth cells migrate downwards to the base of the crypts. Paneth cells secrete several antimicrobial peptides such as defensin [15] and are longer lived than other gut epithelial cells.

\section{The intestinal immune system}

The intestinal immune system is a remarkably complex and diverse ecosystem and has more lymphocytes than any other location in the body. Recent years have brought numerous new insights into crosstalk between the mucosal immune system and both the intestinal epithelium and the microbiota [16]. The intestine contains the largest population of lymphocytes in the body. $\mathrm{CD} 4^{+}$ $\mathrm{T}$ cells modulate intestinal epithelial function and enhance production of antimicrobial peptides during infection, leading to pathogen eradication [17]. Intraepithelial lymphocytes are antigen-experienced $\mathrm{T}$ cells located within the gut epithelium that have immediate access to antigen in the gut lumen [18]. Secretive IgA, which recognizes and coats commensal bacteria, is derived from plasma cells of the germinal center and is abundant in the lamina propria, representing $80 \%$ of all immunoglobulin produced in the body. In addition, innate lymphoid cells, mucosa-associated invariant $\mathrm{T}$ cells, and cells of the mononuclear phagocyte systems all play a role in mucosal immunity [16].

\section{Intestinal microbiota}

Approximately 40 trillion microorganisms reside within the intestine [19], and the number of genes within the microbiome is exponentially larger than that of the human genome [20]. The gut microbiome contains approximately 1000 different species, weighs $1.5 \mathrm{~kg}$, and contains more DNA than every host organ combined [21]. Recent advances in metagenomic sequencing and mass spectrometry reveal that the microbiome plays a pivotal role in maintaining health and homeostasis [22].

\section{The gut in critical illness}

\section{Epithelial alterations and intestinal hyperpermeability}

Apoptosis is upregulated in intestinal epithelial cells following both cecal ligation and puncture and Pseudomonas pneumonia in mice $[23,24]$. Notably, prevention of gut apoptosis by overexpression of B-cell lymphoma 2 (Bcl-2) improves survival in both of these models. In contrast, sepsis induces a profound decrease in crypt proliferation [25]. Migration up the crypt/villus axis is also slowed by critical illness resulting in a marked diminution of villus length [26, 27]. The molecular determinants underlying this are complex with migration occurring more rapidly in mice lacking TLR4 in necrotizing enterocolitis but more slowly in septic mice lacking TLR4. In addition, blocking phosphorylated focal adhesion kinase (P-FAK) leads to a further slowing of enterocyte migration, whereas overexpression of gut-specific Bcl-2 prevents sepsis-induced slowing of enterocyte migration.

Critical illness also induces hyperpermeability of the gut barrier which begins as early as $1 \mathrm{~h}$ after the onset of sepsis and lasts at least $48 \mathrm{~h}$ [28-32]. This impaired barrier function is mediated by changes in the tight junction and associated proteins and allows outflow of luminal contents and likely damages distant organs. Mechanistically, claudin-2 and junctional adhesion molecule (JAM)-A are increased by sepsis, whereas claudin- 5 and occludin are decreased by sepsis. Zonula occludens (ZO)-1 is also variably decreased depending on model system [30, 32-34]. In addition, myosin light chain kinase (MLCK) phosphorylates the myosin regulatory light chain, resulting in contraction of the actin-myosin ring, increasing paracellular permeability. MLCK activation is commonly found with bacterial infection [35, 36], and inhibition of MLCK improves survival in a mouse model of sepsis [37] as well as improving barrier function and tight junction rearrangement in a murine model of burn injury [38]. Of note, changes to the gut epithelium and barrier function are exacerbated in the presence of chronic co-morbidities such as cancer $[39,40]$ or chronic alcohol use [41-43].

Mucus also plays a crucial role in host defense by preventing bacteria and digestive enzymes from coming into contact with the gut epithelium, and the hydrophobic properties of mucus significantly decrease the ability of positively charged, water-soluble toxic molecules to traverse the surface [44]. The mucus layer is damaged during critical illness, which, in turn, results in epithelial cell dysfunction. 
Ischemia/reperfusion leads to a loss of hydrophobicity of the mucus layer and altered intestinal permeability [44]. In addition, after trauma/hemorrhagic shock, rats have decreased mucus and villus height loss with increased epithelial apoptosis and hyperpermeability [28]. Notably, H2 blockers decrease gut mucus production and lead to barrier dysfunction in vitro [45].

\section{The pathobiome}

The density and composition of the microbiota are drastically altered within hours of the onset of critical illness with the conversion of the health-inducing microbiome into a disease-promoting pathobiome [46]. Significant emerging data suggests a link between critical illness and the microbiome. The largest study in the field of critical care examined microbiota in the skin, tongue, and stool of 115 intensive care unit (ICU) patients within $48 \mathrm{~h}$ of ICU admission and ICU discharge or 10th ICU day to over 1000 patients from the American Gut Project [47]. Alpha-diversity (within group) of stool and skin was considerably decreased at ICU admission. At the phylum level, the relative abundance of Firmicutes and Bacteroidetes was decreased, whereas Proteobacteria was increased in the stool of ICU patients. At the genus level, Faecalivacterium, which has anti-inflammatory properties, was massively decreased, but common pathogens Enterobacter and Staphylococcus were increased. Complementary results were demonstrated in a prospective study of 34 ICU patients that showed a significant decrease in Firmicutes and Bacteroidetes and an increase in Proteobacteria compared to 15 healthy controls at the phyla level [48]. At the genus level, Faecalibacterium, Blautia, Ruminococcus, Subdoligranulum, and Pseudobutyrivibrio were all significantly decreased, and overall microbiota diversity was significantly impaired. A loss of microbiota diversity was also observed in a smaller study of 14 septic ICU patients where remarkably $35 \%$ of patients had only 1 to 4 bacterial taxa in their stool [49]. Overall, Proteobacteria was dominant in the ICU, and the number of Firmicutes decreased, whereas Enterococcus, Staphylococcus, and Enterobacter all increased in septic patients. Of note, under basal conditions, the taxa within the gut microbiome are relatively temporally stable although may be impacted by diet and environmental factors [50]. In contrast, the transition to a pathobiome occurs nearly immediately in ICU patients [51]. Dysbiosis progression has also been observed in pediatric ICU patients [52].

The etiology of the instability in the microbiome in critical illness is multifactorial. Critical illness, in isolation, causes profound alterations to the gut microbiota, likely caused by the overall alterations in host milieu. Notably, bacteria can become newly virulent in the setting of critical illness by expressing ancestral or newly acquired genes [53, 54]. In addition, numerous treatments delivered to patients in the ICU have off-target effects that directly alter the microbiome. Drugs that have been shown to impact the microbiome include antibiotics, proton pump inhibitors, and opioids [55, 56]. In addition, nutrition components (carbohydrates, lipid, and protein) and route (enteral/parenteral) alter the microbiome in health [57-59]. Little information is available as to the role nutrition plays on the microbiome in critical illness [60], although a murine study demonstrated increased Bacteroidetes and impaired barrier function following parenteral nutrition, which was reversed by enteral nutrition supplementation [61].

\section{Gut lymph hypothesis}

The gut lymph hypothesis states that noxious mediators originating from the intestinal lumen travel via the mesenteric lymph to the lung where they cause tissue damage. Several pieces of research support this hypothesis. Ligating the mesenteric lymph duct decreases lung injury and attenuates neutrophil activation in rodent models of critical illness with improved survival $[62,63]$. Further, injecting mesenteric lymph from trauma-hemorrhage induces lung hyperpermeability and lung injury [64]. Complementary to this is the gut-lung axis of critical illness [65]. Lung communities are dominated by gut-associated bacteria following murine sepsis, and ecological analysis revealed the gut as the likely source of lung bacteria. This is consistent with the abundance of gut-specific bacteria in ICU patients with acute respiratory distress syndrome [66].

\section{Therapeutic approaches targeting the intestine} Gut epithelial integrity and permeability-basic research No current therapy exists to target the gut epithelium, permeability, or mucus at the bedside of critically ill patients. However, multiple pre-clinical strategies exist that may be potential targets in the future. For example, epidermal growth factor (EGF) has been shown to improve gut apoptosis, proliferation, and permeability following either cecal ligation and puncture or Pseudomonas pneumonia even if started $24 \mathrm{~h}$ after the onset of sepsis [42, 67-69]. Additionally, a membrane permeant inhibitor of MLCK improves intestinal permeability and prevents occludin and $\mathrm{ZO}-1$ reduction following acute alcohol intoxication and burn injury in mice [70]. Administration of a mucus surrogate also prevents trauma/hemorrhagic shock-induced gut injury [71]. In addition, treatment with a pharmacologic vagus nerve agonist attenuates lung injury caused by toxic mesenteric lymph following trauma/hemorrhagic shock in rats [72].

\section{Microbiome-clinical research}

Conceptually, the microbiome can be targeted by increasing "health-promoting" bacteria, decreasing "disease-promoting" bacteria or preventing an alteration in bacterial 
virulence factors. Many of these have been tried in patients with variable results.

Probiotics are exogenous live bacteria administered to the host and have been extensively studied in critical illness. Meta-analyses have demonstrated a decrease in ventilator-associated pneumonia following administration of probiotics, but this has not been accompanied by alterations in mortality or length of stay [73-75]. The evidence is not high quality, however, as the studies have been limited by significant heterogeneity in terms of types of bacteria used, timing of administration, and quality of the studies as well as the fact that the majority of these studies were performed prior to more recent breakthroughs in microbiome analysis. Notably, 4-week administration of probiotics to healthy volunteers does not alter gut microbiota [76]. However, there are questions about sustainability after probiotic administration as well as geographic variation in the intestine whereby the microbiota might resist or enhance colonization based upon probiotic effects [77]. Furthermore, when humans (and mice) are given antibiotics and then given autologous microbiome transplantation (pre-antibiotic stool) or probiotics, one's own stool rapidly reconstituted a normal microbiome but probiotics were associated with a marked delay in return to normal microbiome [78].

Unlike the selective approach of probiotics, fecal microbial transplantation (FMT) is a strategy in which the entire microbiome is transplanted from a healthy donor, with the goal of reconstructing normal commensal flora in the diseased gut. FMT has been demonstrated to be remarkably successful in the treatment of recurrent Clostridium difficile infection with a $92 \%$ response rate to treatment [79]. FMT is also increasingly being used for dysbiosis caused by other intestinal pathology (such as inflammatory bowel disease). The intermediate long-term effects of FMT on the microbiome are not clear as studies to date have shown conflicting results $[80,81]$. To date, data on FMT in the ICU is limited to case reports [82], and its safety and efficacy are currently unknown. Further, many ICU patients receive antimicrobial therapy, which would be expected to alter the microbiome after FMT is performed. As such, FMT should be considered experimental in critical illness currently.

Selective decontamination of the digestive tract (SDD) takes the opposite to probiotics and FMT by targeting pathogenic gut bacteria. SDD has been shown to be effective at improving mortality in multiple studies and meta-analyses originating from environments with low anti-microbial resistance [83]. SDD continues to be controversial because of theoretical concerns that it could induce multidrug resistance [84]. Importantly a recent study randomized over 8000 patients on mechanical ventilation in 13 ICUs with moderate to high levels of antibiotic resistance to (a) a modified version of SDD

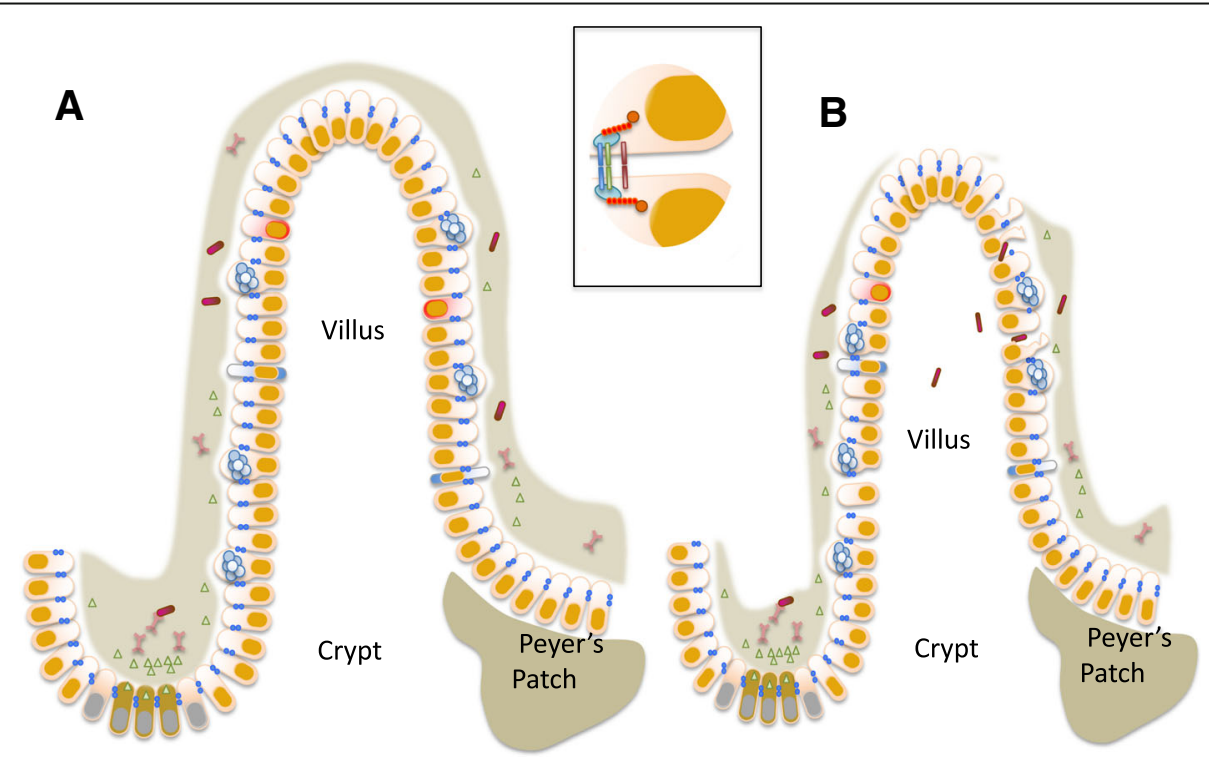

Fig. 1 The gut in health and critical illness. In conditions of health (a), intestinal stem cells proliferate in the crypt (gray and orange), divide into daughter cells, and migrate up in a single-cell layer to the top of the villus. The majority of epithelial cells are enterocytes (white and orange), although there are also goblet cells, enteroendocrine cells, and tuft cells present. The epithelium is surrounded by a continuous mucus layer (gray). This acts as a barrier to luminal microbes (red and green) which are also recognized by secretive IgA (light red). Permeability is also mediated via the tight junction (inset) where a complex machinery between epithelial cells acts as a selective barrier allowing solutes and water through but preventing movement of larger molecules. In critical illness (b), proliferation is decreased and apoptosis is increased leading to a shorter villus length. The mucus layer is damaged and no longer uniform. Along with changes in the tight junction resulting in hyperpermeability, gut barrier function is compromised and bacteria are able to translocate (red rods representing bacteria are present in the lamina propria) 
(without a 4-day course of intravenous antibiotics), (b) selective oropharyngeal decontamination, and (c) chlorhexidine mouthwash and compared them to a baseline period [85]. No reduction in ICU-acquired bloodstream infection or mortality was detected in any of the groups compared to baseline.

\section{Microbiome-basic research}

No bedside therapy exists to prevent induction of new virulence factors in bacteria. However, bench research suggests that bacterial sense intraluminal phosphate, and a lack of phosphate, plays a critical role in the induction of virulence [86]. As such, repletion of intraluminal (not intravenous) phosphate has the potential to trick bacteria into "believing" that a diseased host is healthy. Preclinical data demonstrates that enterally administered polyethylene glycol-conjugated phosphate improves survival in murine intraabdominal sepsis [86].

\section{Conclusions}

All elements of the gut-the epithelium, mucus, the immune system, and the microbiome-are profoundly altered by critical illness compared to health (Fig. 1). Insults to the gut can, in turn, lead to local and distant injury and multiple organ dysfunction syndrome. While therapeutic approaches targeting most of these are several years away from the bedside, several therapeutic approaches currently exist to target the pathobiome. However, none of these is currently standard of care in the ICU, and further research is needed to determine how to target intestinal injury in critical illness.

\section{Abbreviations \\ BCl-2: B-cell lymphoma 2; CD4: Clusters of differentiation 4; EGF: Epidermal growth factor; FMT: Fecal microbial transplantation; ICU: Intensive care unit; JAM-A: Junctional adhesion molecule A; Lgr5: Leucine-rich repeat-containing G protein-coupled receptor 5; MLCK: Myosin light chain kinase; P- FAK: Phosphorylated focal adhesion kinase; PUMA: P53-upregulated modulator of apoptosis; SDD: Selective decontamination of the digestive tract; TLR: Toll-like receptor; ZO-1: Zonula occludens-1}

\section{Acknowledgements}

Not applicable.

\section{Funding}

This work was supported by the National Institutes of Health (GM072808, GM104323, GM109779, GM113228).

\section{Availability of data and materials}

All cited article are available via Pubmed.

\section{Authors' contributions}

SO wrote the manuscript. CMC revised and edited the manuscript. Both authors approved the final manuscript.

Ethics approval and consent to participate Not applicable.

\section{Consent for publication}

Not applicable.

\section{Competing interests}

Both authors declare that they have no competing interests.

\section{Publisher's Note}

Springer Nature remains neutral with regard to jurisdictional claims in published maps and institutional affiliations.

\section{Author details}

${ }^{1}$ Department of Surgery and Emory Critical Care Center, Emory University School of Medicine, 101 Woodruff Circle, Suite WMB 5105, Atlanta, GA 30322, USA. ${ }^{2}$ Department of Emergency and Critical Care Medicine, Chiba University Graduate School of Medicine, Chiba, Japan. ${ }^{3}$ Department of General Medical Science, Graduate School of Medicine, Chiba University, 1-8-1 Inohana,

Chuo-ku, Chiba City, Chiba 260-8670, Japan.

Received: 14 December 2018 Accepted: 6 March 2019

Published online: 20 March 2019

\section{References}

1. Carrico CJ, Meakins JL, Marshall JC, Fry D, Maier RV. Multiple-organ-failure syndrome. The gastrointestinal tract: the "motor" of MOF. Arch Surg. 1986; 121(2):196-208.

2. Clark JA, Coopersmith CM. Intestinal crosstalk: a new paradigm for understanding the gut as the "motor"of critical illness. Shock. 2007;28(4): 384-93.

3. Mittal R, Coopersmith CM. Redefining the gut as the motor of critical illness. Trends Mol Med. 2013;20(4):214-23.

4. Fay $\mathrm{KT}$, Ford $\mathrm{ML}$, Coopersmith $\mathrm{CM}$. The intestinal microenvironment in sepsis. Biochim Biophys Acta. 2017;1863(10 Pt B):2574-83.

5. Lyons JD, Coopersmith CM. Pathophysiology of the gut and the microbiome in the host response. Pediatr Crit Care Med. 2017;18(3_suppl Suppl 1):S46-S9.

6. Meng $\mathrm{M}$, Klingensmith $\mathrm{NJ}$, Coopersmith $\mathrm{CM}$. New insights into the gut as the driver of critical illness and organ failure. Curr Opin Crit Care. 2017;23(2):143-8.

7. Helander HF, Fandriks L. Surface area of the digestive tract - revisited. Scand J Gastroenterol. 2014:49(6):681-9.

8. Allaire JM, Crowley SM, Law HT, Chang SY, Ko HJ, Vallance BA. The intestinal epithelium: central coordinator of mucosal immunity. Trends Immunol. 2018;39(9):677-96.

9. Birchenough GM, Johansson ME, Gustafsson JK, Bergstrom JH, Hansson GC. New developments in goblet cell mucus secretion and function. Mucosal Immunol. 2015;8(4):712-9.

10. Biton M, Haber AL, Rogel N, Burgin G, Beyaz S, Schnell A, et al. T helper cell cytokines modulate intestinal stem cell renewal and differentiation. Cell. 2018;175(5):1307-20.e22

11. Koren E, Yosefzon Y, Ankawa R, Soteriou D, Jacob A, Nevelsky A, et al. ARTS mediates apoptosis and regeneration of the intestinal stem cell niche. Nat Commun. 2018;9(1):4582.

12. Neal MD, Sodhi CP, Jia H, Dyer M, Egan CE, Yazji I, et al. Toll-like receptor 4 is expressed on intestinal stem cells and regulates their proliferation and apoptosis via the p53 up-regulated modulator of apoptosis. J Biol Chem. 2012;287(44):37296-308.

13. Knoop KA, Newberry RD. Goblet cells: multifaceted players in immunity at mucosal surfaces. Mucosal Immunol. 2018:11:1551-7.

14. Gerbe F, Sidot E, Smyth DJ, Ohmoto M, Matsumoto I, Dardalhon V, et al. Intestinal epithelial tuft cells initiate type 2 mucosal immunity to helminth parasites. Nature. 2016;529(7585):226-30.

15. Gassler N. Paneth cells in intestinal physiology and pathophysiology. World journal of gastrointestinal pathophysiology. 2017;8(4):150-60.

16. Powell N, MacDonald TT. Recent advances in gut immunology. Parasite immunology. 2017;39(6)

17. Lu JT, Xu AT, Shen J, Ran ZH. Crosstalk between intestinal epithelial cell and adaptive immune cell in intestinal mucosal immunity. J Gastroenterol Hepatol. 2017;32(5):975-80.

18. Cheroutre H, Lambolez F, Mucida D. The light and dark sides of intestinal intraepithelial lymphocytes. Nat Rev Immunol. 2011;11(7):445-56.

19. Sender R, Fuchs $S$, Milo R. Are we really vastly outnumbered? Revisiting the ratio of bacterial to host cells in humans. Cell. 2016;164(3):337-40.

20. Structure, function and diversity of the healthy human microbiome. Nature. 2012;486(7402):207-14. 
21. Li J, Jia H, Cai X, Zhong H, Feng Q, Sunagawa S, et al. An integrated catalog of reference genes in the human gut microbiome. Nat Biotechnol. 2014; 32(8):834-41.

22. Dickson RP. The microbiome and critical illness. Lancet Respir Med. 2016; 4(1):59-72.

23. Coopersmith CM, Stromberg PE, Dunne WM, Davis CG, Amiot DM, Buchman $\mathrm{TG}$, et al. Inhibition of intestinal epithelial apoptosis and survival in a murine model of pneumonia-induced sepsis. JAMA. 2002;287(13):1716-21.

24. Coopersmith CM, Chang KC, Swanson PE, Tinsley KW, Stromberg PE, Buchman TG, et al. Overexpression of Bcl-2 in the intestinal epithelium improves survival in septic mice. Crit Care Med. 2002;30(1):195-201.

25. Coopersmith CM, Stromberg PE, Davis CG, Dunne WM, Amiot DM, Karl IE, et al. Sepsis from Pseudomonas aeruginosa pneumonia decreases intestinal proliferation and induces gut epithelial cell cycle arrest. Crit Care Med. 2003; 31(6):1630-7.

26. Leaphart CL, Cavallo J, Gribar SC, Cetin S, Li J, Branca MF, et al. A critical role for TLR4 in the pathogenesis of necrotizing enterocolitis by modulating intestinal injury and repair. J Immunol. 2007;179(7):4808-20.

27. Meng $M$, Klingensmith NJ, Liang Z, Lyons JD, Fay KT, Chen CW, et al. Regulators of intestinal epithelial migration in sepsis. Shock. 2018;51(1): 88-96.

28. Rupani B, Caputo FJ, Watkins AC, Vega D, Magnotti LJ, Lu Q, et al. Relationship between disruption of the unstirred mucus layer and intestinal restitution in loss of gut barrier function after trauma hemorrhagic shock. Surgery. 2007;141(4):481-9.

29. Fink MP. Intestinal epithelial hyperpermeability: update on the pathogenesis of gut mucosal barrier dysfunction in critical illness. Curr Opin Crit Care. 2003:9(2):143-51.

30. Yoseph BP, Klingensmith NJ, Liang Z, Breed ER, Burd EM, Mittal R, et al. Mechanisms of intestinal barrier dysfunction in sepsis. Shock. 2016;46(1):52-9.

31. Dominguez JA, Samocha AJ, Liang Z, Burd EM, Farris AB, Coopersmith CM. Inhibition of IKKbeta in enterocytes exacerbates sepsis-induced intestinal injury and worsens mortality. Crit Care Med. 2013;41(10):e275-e85.

32. Li Q, Zhang Q, Wang C, Liu X, Li N, Li J. Disruption of tight junctions during polymicrobial sepsis in vivo. J Pathol. 2009;218(2):210-21.

33. Li GX, Wang XM, Jiang T, Gong JF, Niu LY, Li N. Berberine prevents damage to the intestinal mucosal barrier during early phase of sepsis in rat through mechanisms independent of the NOD-like receptors signaling pathway. Eur J Pharmacol. 2014;730:1-7.

34. Zhou H, Liang H, Li ZF, Xiang H, Liu W, Li JG. Vagus nerve stimulation attenuates intestinal epithelial tight junctions disruption in endotoxemic mice through alpha7 nicotinic acetylcholine receptors. Shock. 2013;40(2):144-51.

35. Jung C, Meinzer U, Montcuquet N, Thachil E, Chateau D, Thiebaut R, et al. Yersinia pseudotuberculosis disrupts intestinal barrier integrity through hematopoietic TLR-2 signaling. J Clin Invest. 2012;122(6):2239-51.

36. Meinzer U, Barreau F, Esmiol-Welterlin S, Jung C, Villard C, Leger T, et al. Yersinia pseudotuberculosis effector YopJ subverts the Nod2/RICKITAK1 pathway and activates caspase-1 to induce intestinal barrier dysfunction. Cell Host Microbe. 2012;11(4):337-51.

37. Lorentz CA, Liang Z, Meng M, Chen CW, Yoseph BP, Breed ER, et al. Myosin light chain kinase knockout improves gut barrier function and confers a survival advantage in polymicrobial sepsis. Molecular medicine (Cambridge, Mass). 2017;23:155-65.

38. Chen C, Wang P, Su Q, Wang S, Wang F. Myosin light chain kinase mediates intestinal barrier disruption following burn injury. PLoS One. 2012:7(4):e34946.

39. Fox AC, Robertson CM, Belt B, Clark AT, Chang KC, Leathersich AM, et al. Cancer causes increased mortality and is associated with altered apoptosis in murine sepsis. Crit Care Med. 2010;38(3):886-93.

40. Lyons JD, Mittal R, Fay KT, Chen CW, Liang Z, Margoles LM, et al. Murine lung cancer increases CD4+ T cell apoptosis and decreases gut proliferative capacity in sepsis. PLoS One. 2016;11(3):e0149069.

41. Yoseph BP, Breed E, Overgaard CE, Ward CJ, Liang Z, Wagener ME, et al. Chronic alcohol ingestion increases mortality and organ injury in a murine model of septic peritonitis. PLoS One. 2013;8(5):e62792.

42. Klingensmith NJ, Yoseph BP, Liang Z, Lyons JD, Burd EM, Margoles LM, et al. Epidermal growth factor improves intestinal integrity and survival in murine sepsis following chronic alcohol ingestion. Shock. 2017;47(2):184-92

43. Klingensmith NJ, Fay KT, Lyons JD, Chen CW, Otani S, Liang Z, et al. Chronic alcohol ingestion worsens survival and alters gut epithelial apoptosis and $\mathrm{Cd} 8+\mathrm{T}$ cell function after Pseudomonas aeruginosa pneumonia-induced sepsis. Shock. 2018.
44. Qin X, Caputo FJ, Xu DZ, Deitch EA. Hydrophobicity of mucosal surface and its relationship to gut barrier function. Shock. 2008;29(3):372-6.

45. Diebel LN, Liberati DM, Hall-Zimmerman L. H2 blockers decrease gut mucus production and lead to barrier dysfunction in vitro. Surgery. 2011;150(4): 736-43.

46. Alverdy JC, Krezalek MA. Collapse of the microbiome, emergence of the pathobiome, and the immunopathology of sepsis. Crit Care Med. 2017;45(2): 337-47.

47. McDonald D, Ackermann G, Khailova L, Baird C, Heyland D, Kozar R, et al. Extreme dysbiosis of the microbiome in critical illness. mSphere. 2016;1(4).

48. Lankelma JM, van Vught LA, Belzer C, Schultz MJ, van der Poll T, de Vos WM, et al. Critically ill patients demonstrate large interpersonal variation in intestinal microbiota dysregulation: a pilot study. Intensive Care Med. 2017; 43(1):59-68

49. Zaborin A, Smith D, Garfield K, Quensen J, Shakhsheer B, Kade M, et al. Membership and behavior of ultra-low-diversity pathogen communities present in the gut of humans during prolonged critical illness. MBio. 2014 5(5):e01361-14.

50. Clemente JC, Ursell LK, Parfrey LW, Knight R. The impact of the gut microbiota on human health: an integrative view. Cell. 2012;148(6):1258-70.

51. Ojima M, Motooka D, Shimizu K, Gotoh K, Shintani A, Yoshiya K, et al. Metagenomic analysis reveals dynamic changes of whole gut microbiota in the acute phase of intensive care unit patients. Dig Dis Sci. 2016;61(6):1628-34

52. Rogers MB, Firek $B$, Shi $M$, Yeh A, Brower-Sinning $R$, Aveson $V$, et al. Disruption of the microbiota across multiple body sites in critically ill children. Microbiome. 2016;4(1):66.

53. Alverdy JC, Luo JN. The influence of host stress on the mechanism of infection: lost microbiomes, emergent pathobiomes, and the role of interkingdom signaling. Front Microbiol. 2017:8:322.

54. Babrowski T, Romanowski K, Fink D, Kim M, Gopalakrishnan V, Zaborina O, et al. The intestinal environment of surgical injury transforms Pseudomonas aeruginosa into a discrete hypervirulent morphotype capable of causing lethal peritonitis. Surgery. 2013;153(1):36-43.

55. Lankelma JM, Cranendonk DR, Belzer C, de Vos AF, de Vos WM, van der Poll $T$, et al. Antibiotic-induced gut microbiota disruption during human endotoxemia: a randomised controlled study. Gut. 2017:66(9):1623-30.

56. Zaborin A, Gerdes S, Holbrook C, Liu DC, Zaborina OY, Alverdy JC. Pseudomonas aeruginosa overrides the virulence inducing effect of opioids when it senses an abundance of phosphate. PLoS One. 2012;7(4):e34883.

57. Wu GD, Chen J, Hoffmann C, Bittinger K, Chen YY, Keilbaugh SA, et al. Linking long-term dietary patterns with gut microbial enterotypes. Science. 2011;334(6052):105-8.

58. Hildebrandt MA, Hoffmann C, Sherrill-Mix SA, Keilbaugh SA, Hamady M, Chen YY, et al. High-fat diet determines the composition of the murine gut microbiome independently of obesity. Gastroenterology. 2009;137(5):1716-24 e1-2.

59. David LA, Maurice CF, Carmody RN, Gootenberg DB, Button JE, Wolfe BE, et al. Diet rapidly and reproducibly alters the human gut microbiome. Nature. 2014;505(7484):559-63.

60. Krezalek MA, Yeh A, Alverdy JC, Morowitz M. Influence of nutrition therapy on the intestinal microbiome. Current opinion in clinical nutrition and metabolic care. 2017;20(2):131-7

61. Wan X, Bi J, Gao X, Tian F, Wang X, Li N, et al. Partial enteral nutrition preserves elements of gut barrier function, including innate immunity, intestinal alkaline phosphatase (IAP) level, and intestinal microbiota in mice. Nutrients. 2015;7(8):6294-312.

62. Badami CD, Senthil M, Caputo FJ, Rupani BJ, Doucet D, Pisarenko V, et al. Mesenteric lymph duct ligation improves survival in a lethal shock model. Shock. 2008;30(6):680-5

63. Deitch EA. Gut-origin sepsis: evolution of a concept. Surgeon. 2012;10(6): 350-6.

64. Senthil M, Watkins A, Barlos D, Xu DZ, Lu Q, Abungu B, et al. Intravenous injection of trauma-hemorrhagic shock mesenteric lymph causes lung injury that is dependent upon activation of the inducible nitric oxide synthase pathway. Ann Surg. 2007;246(5):822-30.

65. Dumas A, Bernard L, Poquet Y, Lugo-Villarino G, Neyrolles $O$. The role of the lung microbiota and the gut-lung axis in respiratory infectious diseases. Cell Microbiol. 2018;20(12):e12966.

66. Dickson RP, Singer BH, Newstead MW, Falkowski NR, Erb-Downward JR, Standiford TJ, et al. Enrichment of the lung microbiome with gut bacteria in sepsis and the acute respiratory distress syndrome. Nat Microbiol. 2016; 1(10):16113. 
67. Clark JA, Clark AT, Hotchkiss RS, Buchman TG, Coopersmith CM. Epidermal growth factor treatment decreases mortality and is associated with improved gut integrity in sepsis. Shock. 2008;30(1):36-42.

68. Clark JA, Gan H, Samocha AJ, Fox AC, Buchman TG, Coopersmith CM. Enterocyte-specific epidermal growth factor prevents barrier dysfunction and improves mortality in murine peritonitis. Am J Physiol Gastrointest Liver Physiol. 2009;297(3):G471-G9.

69. Dominguez JA, Vithayathil PJ, Khailova L, Lawrance CP, Samocha AJ, Jung E, et al. Epidermal growth factor improves survival and prevents intestinal injury in a murine model of pseudomonas aeruginosa pneumonia. Shock. 2011;36(4):381-9.

70. Zahs A, Bird MD, Ramirez L, Turner JR, Choudhry MA, Kovacs EJ. Inhibition of long myosin light-chain kinase activation alleviates intestinal damage after binge ethanol exposure and burn injury. Am J Physiol Gastrointest Liver Physiol. 2012;303(6):G705-G12.

71. Fishman JE, Sheth SU, Levy G, Alli V, Lu Q, Xu D, et al. Intralumina nonbacterial intestinal components control gut and lung injury after trauma hemorrhagic shock. Ann Surg. 2014;260(6):1112-20.

72. Langness S, Costantini TW, Morishita K, Eliceiri BP, Coimbra R. Modulating the biologic activity of mesenteric lymph after traumatic shock decreases systemic inflammation and end organ injury. PLoS One. 2016;11(12):e0168322.

73. Weng $H$, Li JG, Mao Z, Feng $Y$, Wang $C Y$, Ren $X Q$, et al. Probiotics for preventing ventilator-associated pneumonia in mechanically ventilated patients: a meta-analysis with trial sequential analysis. Front Pharmacol. 2017;8:717.

74. Manzanares W, Lemieux M, Langlois PL, Wischmeyer PE. Probiotic and synbiotic therapy in critical illness: a systematic review and meta-analysis. Crit Care. 2016;19:262.

75. Bo L, Li J, Tao T, Bai Y, Ye X, Hotchkiss RS, et al. Probiotics for preventing ventilator-associated pneumonia. Cochrane Database Syst Rev. 2014;10: CD009066.

76. Noh CK, Kim BS, Hong G, Cheong JY, Lee KJ. Effects of the administration of probiotics on fecal microbiota diversity and composition in healthy individuals. Journal of neurogastroenterology and motility. 2018;24(3):452-9.

77. Zmora N, Zilberman-Schapira G, Suez J, Mor U, Dori-Bachash M, Bashiardes $S$, et al. Personalized gut mucosal colonization resistance to empiric probiotics is associated with unique host and microbiome features. Cell. 2018;174(6):1388-405 e21.

78. Suez J, Zmora N, Zilberman-Schapira G, Mor U, Dori-Bachash M, Bashiardes S, et al. Post-antibiotic gut mucosal microbiome reconstitution is impaired by probiotics and improved by autologous FMT. Cell. 2018;174(6):1406-23 e16.

79. Quraishi MN, Widlak M, Bhala N, Moore D, Price M, Sharma N, et al. Systematic review with meta-analysis: the efficacy of faecal microbiota transplantation for the treatment of recurrent and refractory Clostridium difficile infection. Aliment Pharmacol Ther. 2017;46(5):479-93.

80. Khoruts A, Dicksved J, Jansson JK, Sadowsky MJ. Changes in the composition of the human fecal microbiome after bacteriotherapy for recurrent Clostridium difficile-associated diarrhea. J Clin Gastroenterol. 2010; 44(5):354-60.

81. Camacho-Ortiz A, Gutierrez-Delgado EM, Garcia-Mazcorro JF, MendozaOlazaran S, Martinez-Melendez A, Palau-Davila L, et al. Randomized clinical trial to evaluate the effect of fecal microbiota transplant for initial Clostridium difficile infection in intestinal microbiome. PLoS One. 2017; 12(12):e0189768

82. McClave SA, Patel J, Bhutiani N. Should fecal microbial transplantation be used in the ICU? Curr Opin Crit Care. 2018;24(2):105-11.

83. Price R, Maclennan G, Glen J. Selective digestive or oropharyngeal decontamination and topical oropharyngeal chlorhexidine for prevention of death in general intensive care: systematic review and network metaanalysis. BMJ. 2014;348:92197.

84. Sanchez-Ramirez C, Hipola-Escalada S, Cabrera-Santana M, Hernandez-Viera MA, Caipe-Balcazar L, Saavedra P, et al. Long-term use of selective digestive decontamination in an ICU highly endemic for bacterial resistance. Crit Care. 2018;22(1):141

85. Wittekamp BH, Plantinga NL, Cooper BS, Lopez-Contreras J, Coll P, Mancebo $J$, et al. Decontamination strategies and bloodstream infections with antibiotic-resistant microorganisms in ventilated patients: a randomized clinical trial. Jama. 2018;320(20):2087-98.

86. Zaborin A, Defazio JR, Kade M, Kaiser BL, Belogortseva N, Camp DG, et al. Phosphate-containing polyethylene glycol polymers prevent lethal sepsis by multidrug-resistant pathogens. Antimicrob Agents Chemother. 2014;58(2):966-77.

Ready to submit your research? Choose BMC and benefit from:

- fast, convenient online submission

- thorough peer review by experienced researchers in your field

- rapid publication on acceptance

- support for research data, including large and complex data types

- gold Open Access which fosters wider collaboration and increased citations

- maximum visibility for your research: over $100 \mathrm{M}$ website views per year

At BMC, research is always in progress.

Learn more biomedcentral.com/submissions 